\title{
Application of Optical Fiber Sensing Technology in Offshore Platform Structure Monitoring
}

\author{
Jingsheng $L^{1,2, a^{*}}$, Shaodong JIANG ${ }^{1,2, b}$, Chang WANG ${ }^{1,2, c}$, \\ Xiaolei ZHANG ${ }^{1,2, d}$, and Faxiang ZHANG $^{1,2, e}$ \\ ${ }^{1}$ Laser Institute of Shandong Academy of Science, Jinan, 250014, China \\ ${ }^{2}$ Shandong Key laboratory of Fiber Sensing Technology, Jinan, 250014, China \\ a13869101310@163.com, bshdjiang_njust@163.com, cwang960100@163.com, \\ dxiaoleizh85@163.com, ${ }^{\mathrm{e}}$ zhangfx@semi.ac.cn
}

Keywords: Offshore Platform; Optical Fiber Sensing; Structure Monitoring; FBG

Abstract. With increasing service life of offshore platform, the platform components have different degrees of damage and aging. In order to ensure the safety of offshore platform, the structure monitoring need to be implemented. The optical fiber sensing network is composed of FBG(Fiber Bragg Grating) accelerometers, FBG strain sensors, and FBG tilt sensors. The sensing network is used to monitor the displacement, bearing load of pile end, and uneven settlement of offshore platform. The results show that the use of optical fiber sensing technology for offshore platform structure monitoring is a feasible and effective method. This paper is greatly significant for ensuring the safety of offshore platform.

\section{Introduction}

Since 1969s, the oil in Bohai Gulf was begun to explore and develop, and most offshore platforms have entered the subsequent tour of duty. The platform components have different degrees of damage and aging, coupled with the complex in which the marine enviroment, there are many security risks. Therefore, the offshore platform structure monitoring is greatly significant for ensuring the safety of offshore platform.

Compared with the traditional sensing technology, the optical fiber sensing technology has the characteristics of anti-electro magnetic interference, waterproof and moisture, corrosion resistance, easy to realize network sensing and so on[1]. Therefore, the optical fiber sensing technology is more applicable to the moist and highly corrosive environment of the offshore platform. The displacement, bearing load of pile end, and uneven settlement are the main contents of offshore platform structure monitoring[2]. In this paper, a veriety of FBG sensors are used to form the optical fiber sensing network. The offshore platform structure monitoring is implemented, and the monitoring results are given.

\section{Structure Monitoring}

The monitored offshore platform in this paper is a jacket platform, which has 8 main piles, 4 skirt piles, as shown in Fig.1.

Displacement Monitoring. The acceleration of the platform is measured by FBG accelerometers. Then the displacement of the platform is obtained by solving the second integral on acceleration. The FBG accelerometer is shown in Fig.2.

8 FBG accelerometers are arranged on the transverse beams at platform deck pillars, as shown in Fig.3. 


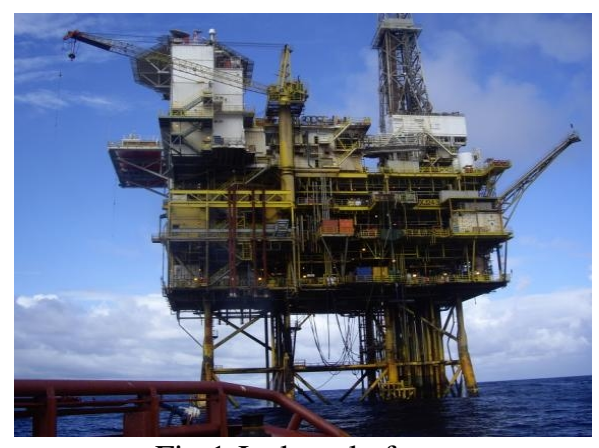

Fig.1 Jacket platform

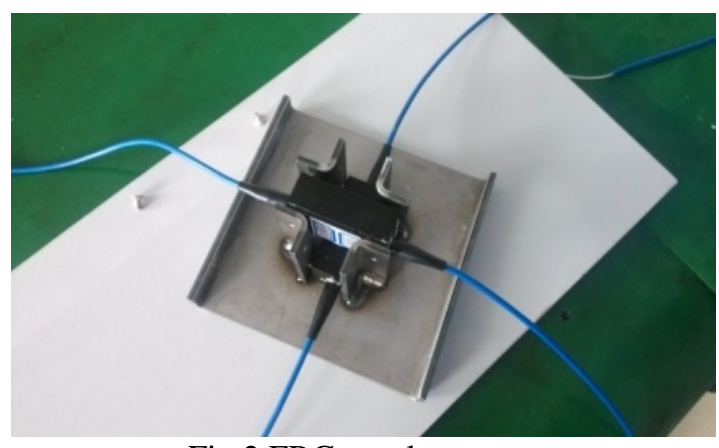

Fig. 2 FBG accelerometer

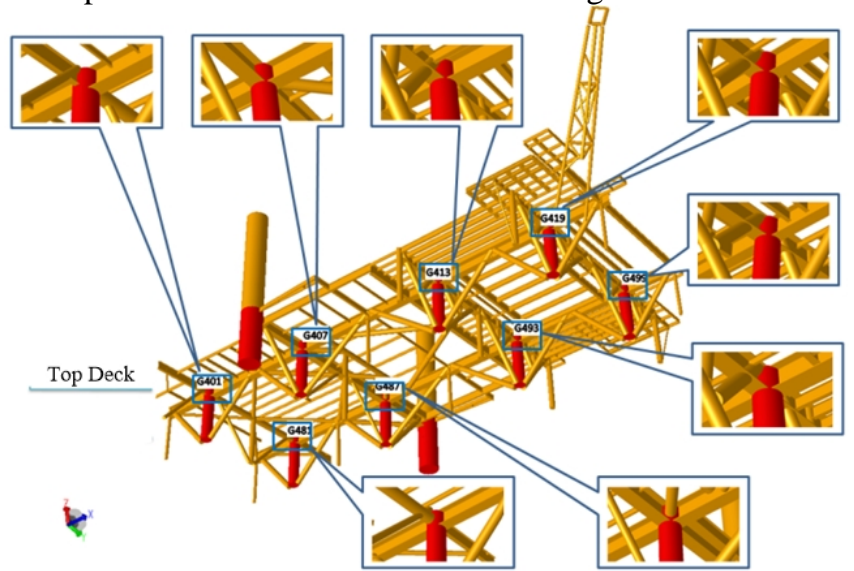

Fig.3 Position of accelerometers

Bearing Load of Pile End Monitoring. The strain of pile-leg can be measured through FBG strain sensors, then the bearing load of pile end can be obtained through the theoretical derivation $[3,4]$. The FBG strain sensor is shown in Fig.4.

Near the bottom of the deck pile-leg upright area, the strain sensor is installed at intervals of $90^{\circ}$, as shown in Fig.5.

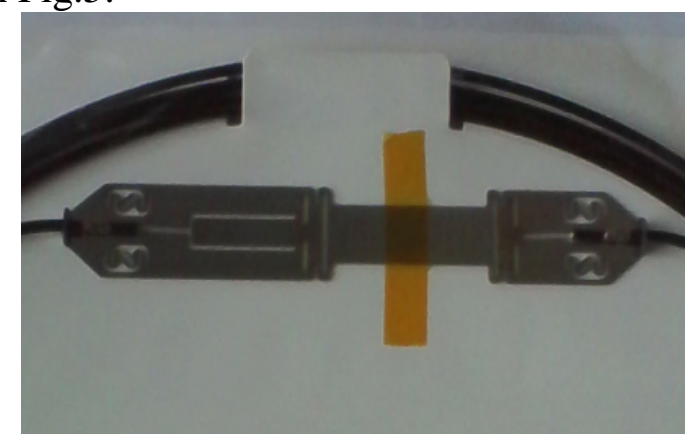

Fig.4 FBG strain sensor

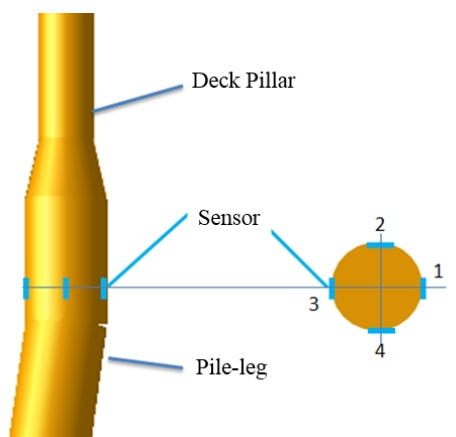

Fig.5 Position of strain sensors

Uneven Settlement Monitoring. The strain at both ends of the transverse beam can be measured through FBG strain sensors, and the tilt at the middle of the transverse beam can be measured through FBG tilt sensors. Then the difference in elevation between adjacent piles can be obtained through the theoretical derivation[5,6]. The level of the uneven settlement is reflected by the difference in elevation between adjacent piles. The FBG tilt sensor is shown in Fig.6.

A tilt sensor is arranged between the two pile-legs on the transverse beam of the bottom surface of the bottom deck. And the strain sensors are arranged on both side of the transverse beam, which are used to eliminate measurement errors. The position of strain sensors and tilt sensors is shown in Fig.7.
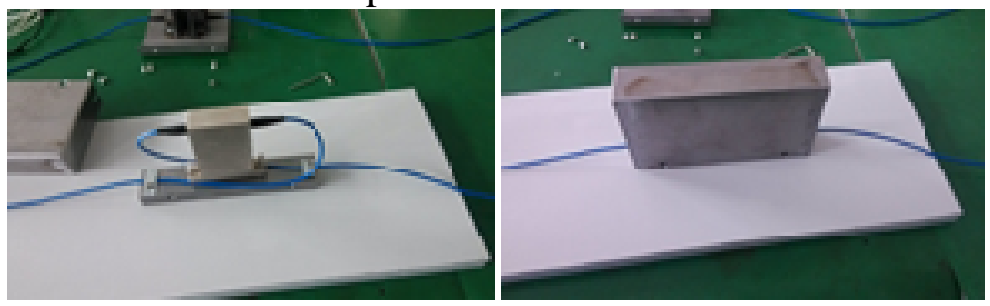

Fig.6 FBG tilt sensor 


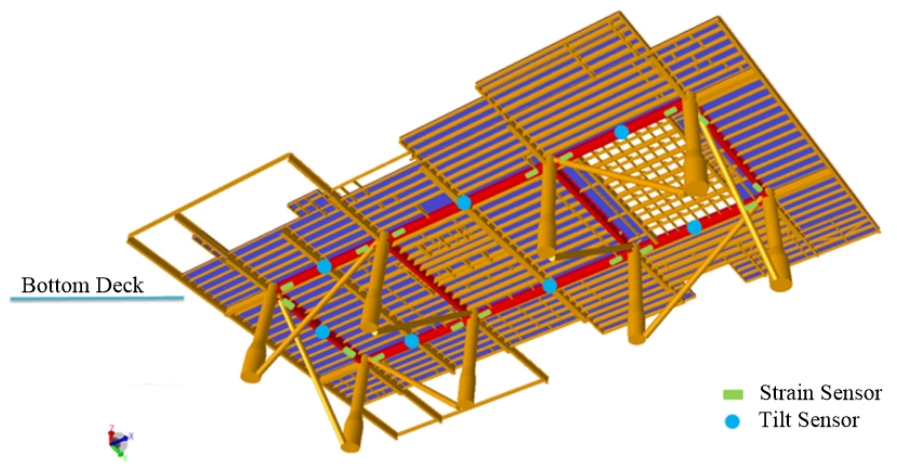

Fig.7 Position of strain sensors and tilt sensors

\section{Results Analysis}

Monitoring Results of Displacement. During the operation of the monitoring system, the displacement monitoring data at a certain time is selected, as shown in Tab.1. Tab.1 shows the measured displaceement mainly along the $\mathrm{Y}$ direction, which is the result of the sea wind along $\mathrm{Y}$ direction.

Tab.1 Displacement Monitoring Data

\begin{tabular}{ccc}
\hline Pile-leg & Displacement Along X $(\mathrm{cm})$ & Displacement Along Y $(\mathrm{cm})$ \\
\hline A1 & -0.50 & -6.79 \\
A2 & -0.45 & -6.99 \\
A3 & -0.40 & -7.08 \\
A4 & -0.33 & -7.11 \\
B1 & -0.34 & -6.66 \\
B2 & -0.26 & -6.68 \\
B3 & -0.18 & -6.68 \\
B4 & -0.09 & -7.10 \\
\hline
\end{tabular}

Monitoring Results of Bearing Load of Pile End. Fig.8 shows the monitoring results of the pile-leg strain, which including both normal weather and typhoon weather. In Fig.8, the black curve is the bearing force of pile end, the green curve is the wind speed, and the blue curve is the wind direction. As can be seen from Fig.8, the wind speed and wind direction in May 30th were stationary, but in June 10th the wind speed increased and the wind direction changed. Therefore, the bearing force of pile end in June 10th significantly decreased compared with the bearing force in May 30th.

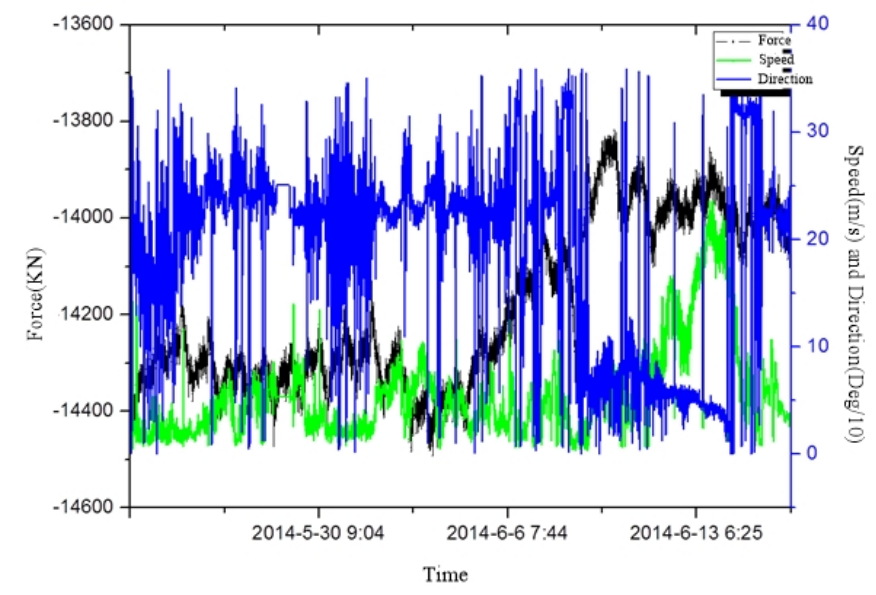

Fig.8 Strain of Pile-leg

Monitoring Results of Uneven Settlement. Fig.9 shows the monitoring results of the uneven settlement, which including both normal weather and typhoon weather. In Fig.9, the black curve is the relative settlement, and the red curve is the early warning line. As known in Fig.9, the uneven 
settlement of the typhoon weather (June 14th, wind speed was $22 \mathrm{~m} / \mathrm{s}$ ) was not significantly changed compared with the normal weather (June 8th, wind speed was $3 \mathrm{~m} / \mathrm{s}$ ). This is due to the uneven settlement is occurring slowly in the long-term service process of the platform, and the short-term typhoon will not affect the uneven settlement.

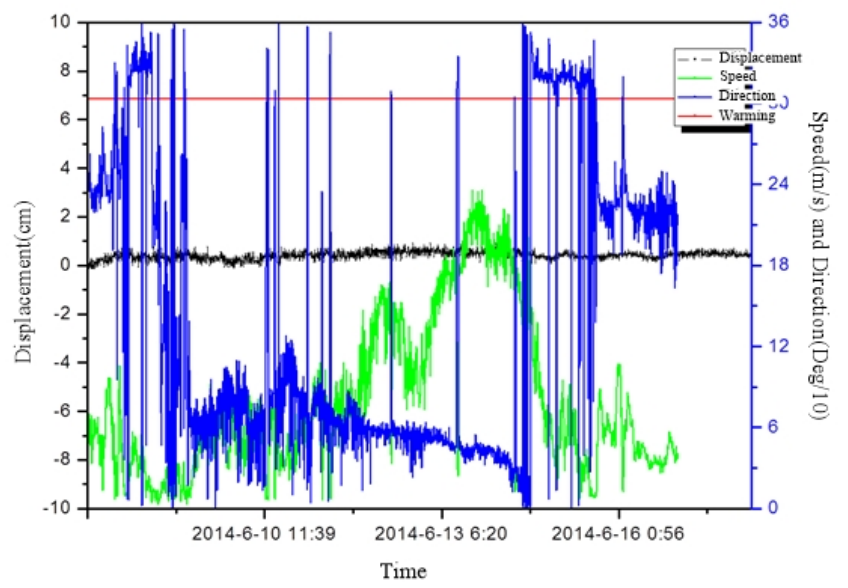

Fig.9 Uneven Settlement of Pile-leg

\section{Conclusion}

In this paper, the offshore platform structure monitoring is realized by using optical fiber sensing technology, based on the security requirement. The optical fiber sensing network is composed of FBG accelerometers, FBG strain sensors, and FBG tilt sensors. The displacement, bearing load of pile end, and uneven settlement of offshore platform are monitored by using the sensing network. The monitoring method and the layout position of sensors are given, and the monitoring results are analyzed. Monitoring results show that it is a feasible and effective method to use the optical fiber sensing technology to implement structural monitoring on offshore platform, which is great significance to ensure the safety of offshore platform.

\section{Acknowledgments}

This work was supported by the Chinese National Natural Science Foundation (No. 61205083), Major Research Project of Shandong Province (No. 2015GSF115006), and Science and Technology Development Plan Project of Shandong Province (No. 2014GGX103005).

\section{References}

[1] Giallorenzi T G. Optical fiber sensor technology[C]. Electron Devices Meeting, 1985 International. IEEE, 1985:116-116.

[2] Yue Q J, Wang S Y, Fan Z L, et al.. Vibration monitoring and safety assessment of PY30-1 jacket platform structure[J]. The Ocean Engineering, 2013, 31(2): 41-45.

[3] Xiao Y q, Ou J p, Zhang X c, Pan D M. Impact analysis of flaw and damage on ultimate strength of jacket type offshore steel structures[J]. China Offshore Oil And Gas, 1999, 11(6):16-24.

[4] Xu D, Yue Q J, Zhang Q, et al.. Live load status monitoring of offshore platform using FBG strain sensor[J]. The Ocean Engineering, 2008,26(4):24-26.

[5] Wang Y L, Yue Q J, Zhu X H, et al.. Subsidence monitoring of jacket oil platforms[J]. The Ocean Engineering,2010,28(4):122-126.

[6] Song X Z. Settlement analysis of the pile foundations of the offshore platform based on field monitoring[D]. Dalian University Of Technology, 2011. 